\title{
Abortion and infant mortality change driven by socioeconomic conditions in Russia
}

\author{
Li Wang, ${ }^{1}$ Linsheng Yang, ${ }^{1}$ Hairong Li, ${ }^{1}$ Hongyan Cai, ${ }^{2}$ Jixia Huang, ${ }^{1,3}$ \\ Svetlana M. Malkhazova ${ }^{4}$
}

\author{
${ }^{1}$ Key Laboratory of Land Surface Pattern and Simulation, Institute of Geographical Sciences and Natural \\ Resources Research, Chinese Academy of Sciences, Beijing, China; ${ }^{2}$ State Key Laboratory of Resources and \\ Environmental Information System, Institute of Geographical Sciences and Natural Resources Research, \\ Chinese Academy of Sciences, Beijing, China; ${ }^{3}$ Key Laboratory for Silviculture and Conservation of \\ Ministry of Education, Beijing Forestry University, Beijing, China; ${ }^{4}$ Faculty of Geography, Lomonosov \\ Moscow State University, Moscow, Russian Federation
}

\begin{abstract}
Correspondence: Hairong Li, Key Laboratory of Land Surface Pattern and Simulation, Institute of Geographical Sciences and Natural Resources Research, Chinese Academy of Sciences, Beijing 100101, China.

E-mail: lihr@igsnrr.ac.cn ; huangjx@bjfu.edu.cn

Key words: Abortion; infant mortality; spatial econometric model; Russia. between AR and infant mortality that was evident earlier, but not in the recent years, implies that the health care system in Russia is effective. A comprehensive improvement in wellbeing, income, etc. can contribute to mitigation of abortion and infant mortality. Theoretically, this study extends current research by comprehensively displaying the spatio-temporal patterns of abortion and infant mortality in Russia and qualifies the impact of regional socioeconomic disparities with regard to these two issues.
\end{abstract}

Acknowledgements: LW and LY conceived the study and wrote the manuscript; JH and $\mathrm{HC}$ conducted the modelling; SMM provided very in-deep suggestions on the study.

Funding: this study is funded by the National Natural Science Foundation of China (42007414, 42061134019), the Strategic Priority Research Program of the Chinese Academy of Sciences (No. XDA19070502) and the Key project of the Chinese Academy of Sciences (No. ZDRW-ZS-2017-4).

Conflict of interests: the authors declare no potential conflict of interests.

See online Appendix for additional Figures and Tables.

Received for publication: 16 July 2020

Revision received: 29 December 2020.

Accepted for publication: 31 December 2020.

CCopyright: the Author(s), 2021

Licensee PAGEPress, Italy

Geospatial Health 2021; 16:923

doi:10.4081/gh.2021.923

This article is distributed under the terms of the Creative Commons Attribution Noncommercial License (CC BY-NC 4.0) which permits any noncommercial use, distribution, and reproduction in any medium, provided the original author(s) and source are credited. extremely high abortion rate (AR) and a generally high mortality, panel economic analysis using data from the 83 regions of the country covering four time periods was applied. Every 1000 USD increase in per capita gross regional product (GRP) can lead to a decrease of the AR by 0.075 , while one year life expectancy increase would lower it by 0.441 . For infant mortality rate (IMR), GRP also shows a positive impact, particularly in recent years, while the population size of the region has a negative impact. Every 1000 USD increase in per capita GRP would result in a rate decrease of 0.064 in IMR, and every increase of 1000 added population would lead to an increased IMR by 2.05 . The harvest effect

\section{Introduction}

Russia has been experiencing a nationwide population decline in the past decades, mainly attributable to extremely low fertility, including infant mortality and labour mortality. This demographical transition has significantly constrained the economic development, as president Putin said in a speech to the Russian parliament in 2006. He emphasized that the demographical issue is the most acute problem for contemporary Russia, for the first time mentioning that it concerns security as well as the rise and fall of the nation (Rosenberg et al., 2018). In order to promote population growth, the government has introduced a series of policies covering taxation, economic incentive, subsidy, etc. to improve fertility and health care (Ministry of Labour of Russia, 2013; Miljkovic and Glazyrina, 2015; National Healthcare Project, 2018; Luneva et al., 2019). In general, these strategies have achieved some progress with two milestones in 2007: for the first time during the observation period, the annual number of births exceeded the number of terminated pregnancies (ratio of abortion against live birth $=918.6$ per 1000); and in 2012, the birth rate outpaced the total mortality rate for the first time since the collapse of Soviet Union. However, despite favourable dynamics, the AR is still 
higher than that of developed countries, and the infant mortality rate (IMR) is much higher than the average level reported in developed countries (OECD, 2020). Russia aims to reach a net population growth by 2024 , even though Mr Putin considered this an overly optimistic goal in his speech to the Russian parliament in 2019 (Russian government, 2019).

Russia legalized abortion in 1920 , which partly remains as a legacy of the Soviet times when it was the primary form of birth control. It was the first country to do so and despite a significant decline of the AR recently (Sakevich and Denisov, 2014; Denisov and Sakevich, 2015), it still has one of the highest ARs in the world. The reason is a combination of social and economic conditions (Miljkovic and Glazyrina, 2015; Popov and Tcherenev, 2018; Zhukov, 2018). Denisov and Sakevich (2015) found a declining abortion dynamic in Russia, particularly among the youngest women, and at the national level, they did not find any obvious difference between abortion risks and social characteristics, such as income or education. At the individual level in the period 19001924, women with higher education in Russia might have had higher AR (Gens, 1926). However, based on a recent cross-sectional study in St. Petersburg, Panova et al. (2016) found that low education, excessive drinking, low age at the sexual debut and a fragmented family structure are the key factors for unwanted pregnancies that lead to abortion.

IMR is one of the main health indicators as it reflects healthcare priorities and performance of social insurance programmes (Baranov et al., 2016). In Russia, approximately 55\%-65\% of all deaths in the age group 0-14 years occur among children aged less than one year (Ivanov et al., 2017). Based on a country-level study, Schell et al. (2007) found that, in low-income countries, women's education level is strongly negatively related to infant mortality; the less income, the stronger the negative correlation. An individual-level study based on odds ratio (OR) evaluations in north-western Russia indicates that education is the most significant factor associated with poor infant outcome $(\mathrm{OR}=1.9,95 \%)$; this was discovered by Grjibovski et al. (2002) when comparing secondary or less education with 3 years or more of university studies. At the regional level, Grigoriev et al. (2016) found that the educational quotients positively contributed to mitigation of infant mortality. According to Ivanov et al. (2017), the correlation between income and IMR in Russia has become more significant since 2011 indicating that personal economy plays a more and more important role in infant mortality, while the increasing health expenditure seems to have a very small influence on infant mortality in Russia (Schell et al., 2007; Rosenberg et al., 2018).

The role played by the socioeconomic conditions with regard to abortion and infant mortality in Russia is still controversial. The hypothesis of this study is that the spatial variations of infant mortality and AR are related to socioeconomic status and wellbeing, and that the impact might have both spillover and lag effects. The objectives were to explore the spatial and temporal pattern of abortion and infant mortality by investigating how socioeconomic conditions and wellbeing affect these two demographical indicators.

\section{Materials and methods}

\section{Areas covered and data collected}

This study was conducted using data covering Russia's 83 regions, including first-level administrative divisions (oblasts), republics, autonomous governorates, lower-level administrative divisions (krais), and the cities Moscow and St. Petersburg. Provincial-level socioeconomic data, including unemployment rate, per capita gross regional product (GRP), urbanization rate, total population as well as health data including life expectancy, IMR and AR, were all obtained from the Russia Federal State Statistic Service for the annual periods 2000, 2004 (alternatively 2005), 2010 and 2016 (alternatively 2015 or 2017). The number of abortions per 100 live births, including both induced abortions and miscarriages, was taken as the AR, while that used for infant mortality was the number of deaths per 1000 live births of children less than one year old. The urbanization rate was calculated as the percentage urban population of the total population. The education index was obtained from the National Human Development Report for the Russian Federation for 2000, 2004, 2010 and 2015. Life expectancy was used as an independent variable representing the general health-related well-being of the region. Covariates included in the study are listed in Table S1.

\section{Analysis methods}

$\mathrm{AR}$ and IMR were set as dependent variables. First, we conducted Pearson's correlation and spatial autocorrelation analysis to give a general picture of the variables. Spatial econometric analysis was then used to explore the driving mechanism for AR and IMRs. Pearson correlation between health indicators and variables was conducted using SPSS (IBM, Chicago, IL, USA) and ArcGIS10.2 (ESRI, Redlands, CA, USA) was applied for global autocorrelation and regional agglomeration analysis, including Global Moran's $I$, which varies between $-1 \sim 1$. The local indicators of spatial association statistics indicates clustering pattern between one region and surrounding ones, where the $\mathrm{Z}$ value threshold is usually set at 1.65 ; thus, the chance that a dataset is spatially clustered increases with $\mathrm{Z}$-values above this value together with a $\mathrm{P}$ value lower than 0.05 (or 0.01 ). The detailed methodology for spatial econometric analysis and the latter two approaches have been described by Anselin (1995) and Wang et al. (2019).

Traditional regression analysis does not include spatial correlation but spatial econometric analysis compensates for this deficiency (Anselin, 1990; Wong and Lee, 2005) through dealing with the lag effect of the dependent variable, which is called spatial lag model (SLM) or the spatial autoregressive model. SLM can be used to explore the space overflow effect of the factors and was used in this study to investigate whether the AR, alternatively the IMR (as dependent variables), in one region is influenced by the factors (the independent variables) from this region and/or is also related to factors from neighbourhood regions. The spatial error model (SEM) (Lesage and Pace, 2009) explains correlations through the spatial lag of the deviations and this approach was used to measure the impact of the AR and IMR deviations on neighbourhoods at the regional level. When considering the correlation between the spatial lag of independent variables and dependent variables, spatial auto-correlation shows a lag effect from both independent variables and dependent variables. In this case, the model is spatial Durbin model (SDM) (Lesage and Pace, 2009), which uses both endogenous and exogenous interaction. When there is no lag effect from the independent variables (exogenous interaction), SDM becomes SLM; when there is no lag effect from the dependent variables (endogenous interaction), SDM becomes SEM. 


\section{Model selection}

The statistical test method introduced by Lesage and Pace (2009) was used to choose the best-fit model. For the AR calculations, four steps were conducted.

i) First, the simple ordinary least squares technique is run on panel data with fixed estimates for space, time and spatio-temporal outcomes. In time-fixed and space-fixed lag models $\left(\mathrm{LM}_{\text {lag }}\right)$, significantly $(\mathrm{P}=1 \%, 5 \%)$ rejects the hypothesis of absence of a spatial effect of the variables on AR, indicating spatial effect should be included. When R_LM $\mathrm{LM}_{\text {lag }}$ and R_LM $\mathrm{LM}_{\text {error }}$ significantly reject this hypothesis, it is necessary to use the SDM model applying the Wald and likely-ration (LR) tests to see if SDM can be simplified to SLM or SEM. However, if none of the four parameters in the space-time fixed models, $\left(\mathrm{LM}_{\text {lag }}, \mathrm{R}_{-} \mathrm{LM}_{\text {lag }}, \mathrm{LM}_{\text {error }}\right.$ and $\left.\mathrm{R} \_\mathrm{LM}_{\text {error }}\right)$ reached significance, the hypothesis is allowed (Table S2). Thus, it is necessary to combine $\mathrm{LR}_{\text {space }}$ and $\mathrm{LR}_{\text {time }}$ together to see which fixed model to choose.

ii) If the P-values from both space fixed effects and the time fixed effects are significant in the LR test $(\mathrm{P}<0.001)$, the null hypothesis of no space or time fixed effects is rejected (Table S3) and the next step requires inclusion of both time and space effect in the space panel model.

iii) If the LR and Wald tests reject SDM to be simplified to SEM or SLM at the $5 \%$ level significance in the three different fixed models, it will be necessary to conduct space-fixed SLM, SEM and SDM as well as time-fixed SLM and SDM, compare the result and select the best-fit model.

iv) Comparing the results from space-fixed SLM, SEM and SDM with those emanating from time-fixed SLM and SDM, the significance of the estimation coefficients of the explanatory variables, i.e. the corrected R2, and Log-likelihood (Table S5) indicate the space-fixed SDM model as the best-fit model. Using a similar procedure for IMR, chooses the space-fixed SDM model as the best-fit model for IMR (Tables S6-S9).

\section{Model result interpretation}

Tables 1 and 2 represent the model results of the independent variables' impact on dependent variables AR and IMR. The direct

Table 1. Direct and indirect effects of different factors on abortion rate in Russia.

\begin{tabular}{|c|c|c|c|c|}
\hline Factors & Coefficient & Direct & Indirect & Total \\
\hline Unemployment rate & 0.067345 & $0.105188 * *$ & $0.627109^{* * *}$ & $0.732297^{* * *}$ \\
\hline GRP & $-0.000071^{* * *}$ & $-0.000075^{* * *}$ & $-0.000069 *$ & $-0.000145^{* * *}$ \\
\hline Education index & 6.726972 & 11.015764 & $66.954659 * * *$ & $77.970423^{* * *}$ \\
\hline Urbanization rate & 0.082401 & 0.037454 & $-0.699091^{* *}$ & $-0.661637^{*}$ \\
\hline Life expectancy & $-0.433857^{* * *}$ & $-0.441723^{* * *}$ & -0.180049 & $-0.621772 * * *$ \\
\hline Total population & $0.003394^{* * *}$ & $0.003825^{* * *}$ & $0.006718^{* * *}$ & $0.010543^{* * *}$ \\
\hline W*Unemployment rate & $0.392554^{* * *}$ & & & \\
\hline $\mathrm{W}^{*} \mathrm{GRP}$ & -0.000021 & 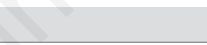 & & \\
\hline $\mathrm{W}^{*}$ Education index & $42.203621^{* * *}$ & & & \\
\hline $\mathrm{W}^{*}$ Urbanization rate & $-0.493688^{* *}$ & Hausman test & & \\
\hline $\mathrm{W}^{*}$ Life_expectancy & 0.042921 & $129.3381^{* * *}$ & & \\
\hline W*Total population & $0.003261^{*}$ & \multicolumn{3}{|c|}{ W*dep.var z-probability } \\
\hline $\mathrm{W}^{*}$ dep.var. & $0.372977^{* * *}$ & $<0.001$ & - & - \\
\hline
\end{tabular}

***Significance at the $1 \%$ confidence level; ${ }^{* *}$ significance at the $5 \%$ confidence level; ${ }^{*}$ significance at the $10 \%$ confidence level. GRP, gross regional product.

Table 2. Direct and indirect effects of different factors on infant mortality rate in Russia.

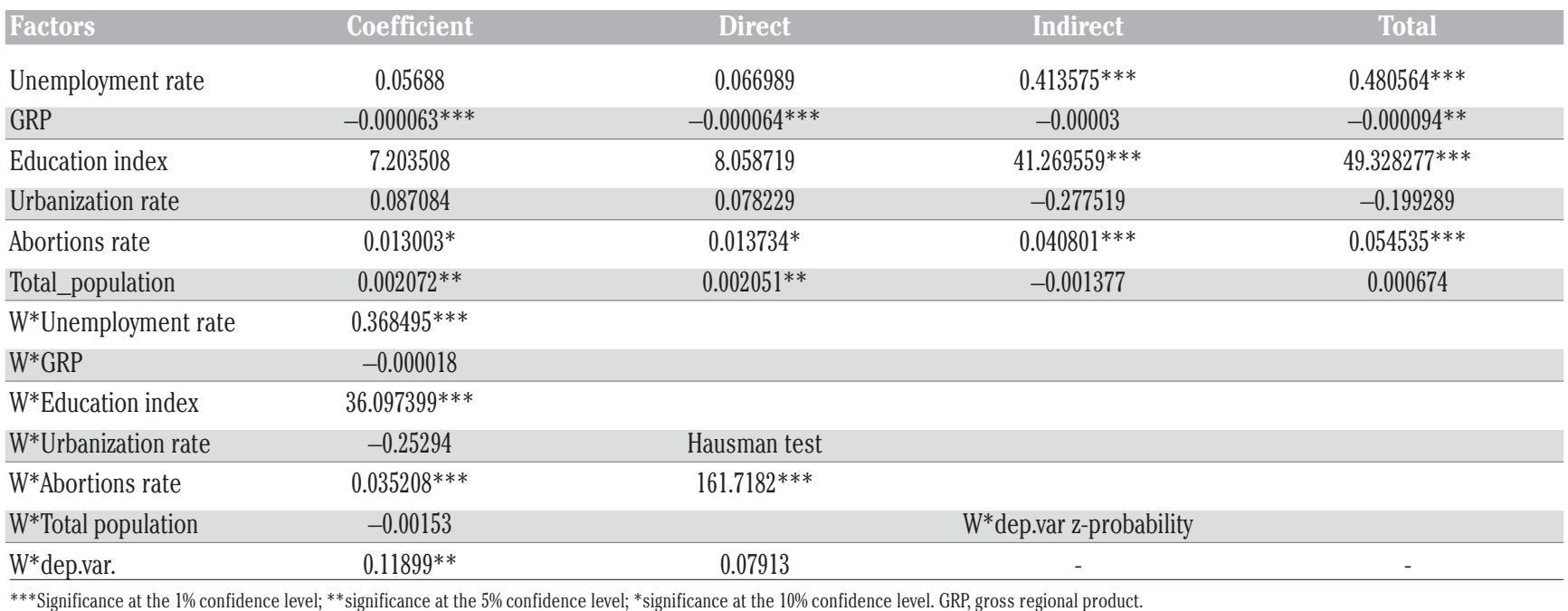


effect with significance indicates that the factor can affect the dependent variables. The indirect effect with significance indicates that the factor of the neighbouring area can affect the dependent variables, which is a spillover effect. The level of direct or indirect effect shows the extent of the impact, for example, the direct effect of GRP on AR (Table 1) is $-0.000075^{* * *}$, which means every oneunit GRP increase makes the AR decrease by 0.000075 . The estimated value of spatial autocorrelation coefficient ( $\mathrm{W}^{*}$ dep.var.) being significant at the $1 \%$ level indicates that the dependent values (AR and IMR) are spatially correlated. The Hausman test hypothesis is that there is no difference between a random-effect model and fixed model, but when it is significant at the $1 \%$ confidence level (Tables 1 and 2), it rejects the random-effect model favouring the fixed-effect model, which indicates that the spacefixed SDM passed the test.

\section{Results}

\section{Statistical description}

The AR decreased significantly in the past decades from 202.4 per 100 live births in 2001 to 43.7 in 2015 , though the level is still high in comparison to the level of the European Union (EU) in 2015 (20.3). At the Russian regional level, the ARs have experienced a general, significant decline since 2000 (Figure 1). In 2000, the highest AR was in Khabarovsk Kray with 239 abortions per 100 live births; in 2005 it was in Vologda Oblast with 206 abortions per 100 live births; and in 2010 in Magadan Oblast with 129 abortions per 100 live births. In the nation as a whole, the ARs in 2015 ranged from a minimum of 12 in Dagestan Republic to the maximum of 105 in Magadan Oblast with an average of 54.38 abortions per 100 live births. The border regions in the South had mainly low ARs, while the eastern coastal and north-western regions showed considerably higher ones.

The IMR has shown a distinguished regional difference by longitude in the earlier years (2000, 2005 and 2010), and the regions with higher infant mortality were mainly located in the East. The highest IMR was found in the Chechen-Ingush Republic, with 33.0 and 25.7 both in 2000 and 2005, respectively, and Tyva Republic, with 16.1 in 2010. More recently, the IMR ranged from 2.5 in Nenets Oblast to 16.1 in Chukchi Republic with a national wide average of 6.3 per 1,000 live births (Figure 2).

\section{Correlation analysis}

The Pearson correlations between AR and IMR with indepen-
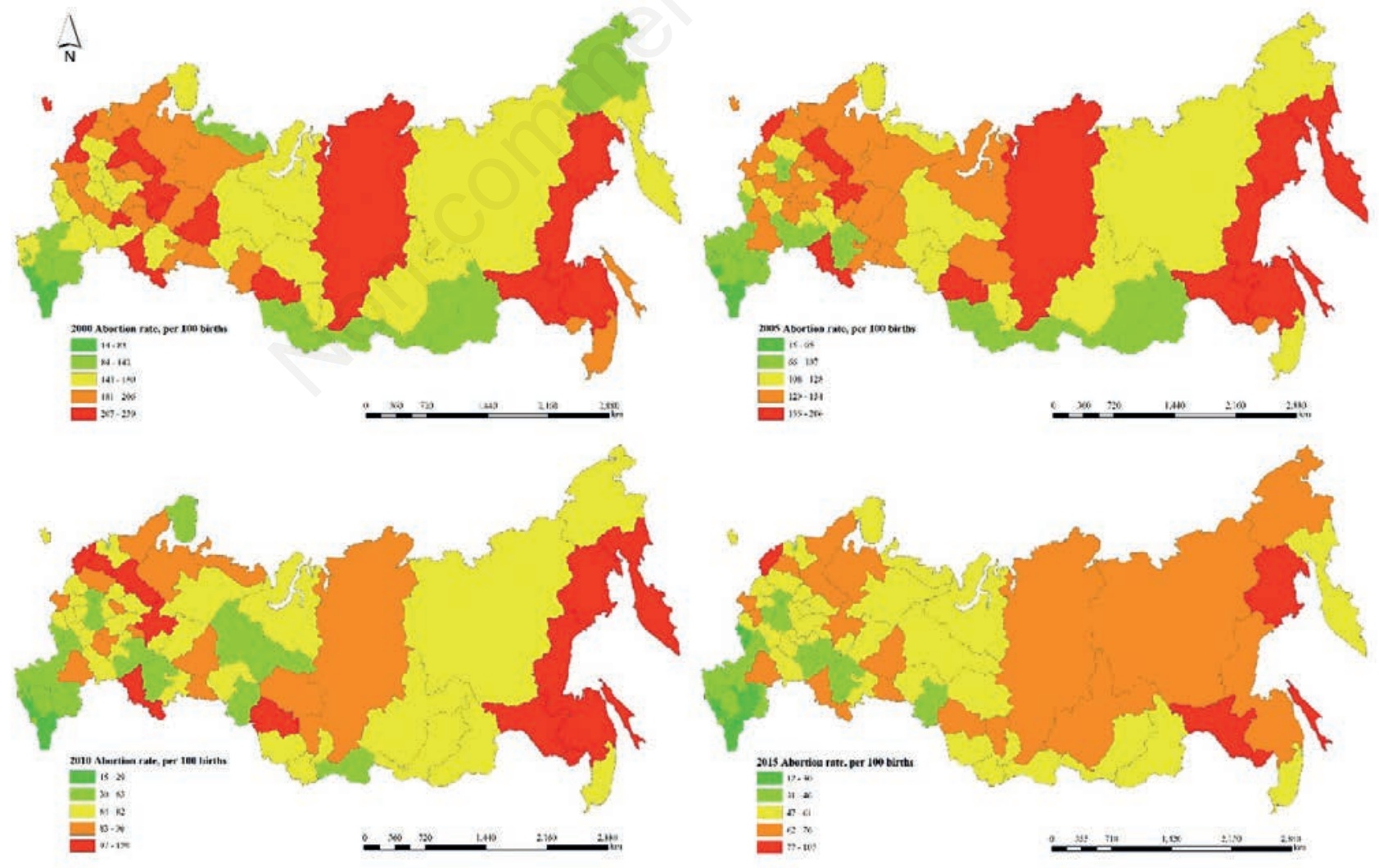

Figure 1. The spatial distribution of the abortion rate in Russia. 
dent variables are listed in Table 3. For AR, negative correlations (at $\mathrm{P}<0.05$ ) were found for unemployment and life expectancy, while positive correlation was found for urbanization in the four time periods investigated indicating that these confounders play significant roles for AR. For education, no correlation was found in the earlier years, while a positive correlation showed up in the more recent years indicating that regions with a higher education level also have a higher tendency to utilize abortion. Although this is counterintuitive, it is in concordance with research showing that women with higher education tend to have low fertility due to a high AR (Sakevich and Denisov, 2014).

Unemployment rate and urbanization rate were positively associated with IMR in the four periods, while AR was negatively correlated with IMR in 2000 , but not so in recent years.

\section{Spatial clustering}

Global Moran's $I$ indicated a spatial autocorrelation for AR and IMR (Table 4). For AR, spatial autocorrelations showed up in the four years selected (at $\mathrm{P}<0.001$ ) and also for IMR, but only in 2010 (at $\mathrm{P}<0.001)$ and in $2016(\mathrm{P}<0.05)$. For $\mathrm{AR}$, the aggregation patterns were mainly the same in the four periods studied, with lowlow areas clustering in the south-eastern regions, neighbouring Ukraine and Georgia, while they were high-high in areas mainly located in western and north-eastern regions (Figure S2). For IMR
(Figure S3), the aggregation pattern in 2000 and 2010 were almost the same with low-low areas clustering in the Northwest and highhigh areas clustering in central and eastern Russia. In 2005 the low-low spots were found to be scattered in the Northeast, with the high-high spots clustered in central Russia, while in 2016, the lowlow spots were mainly located in areas surrounding YamaloNenets and the high-high spots in regions bordering Mongolia.

\section{Spatial panel analysis}

The direct and indirect effects of the different factors favouring AR and IMR can be found in Tables 1 and 2, respectively. The estimations show that the per capita GRP and life expectancy had a negative effect for AR (at the $1 \%$ level), while the total populations in the various regions were found to have a positive effect for AR (at the $1 \%$ level). This means that a higher per capita GRP and wellbeing, e.g., better health and decreasing AR; however, the larger the population size, the higher the AR. Per capita GRP and total population also showed spillover effects (indirect effects), confirming that better wellbeing and a smaller size of the population contributes to AR mitigation.

Specifically, every 1000 USD increase in the per capita GRP would lead to a decrease of $0.075 \mathrm{AR}$ in the region, and every one year increase in life expectancy would lead to a decrease of 44.1
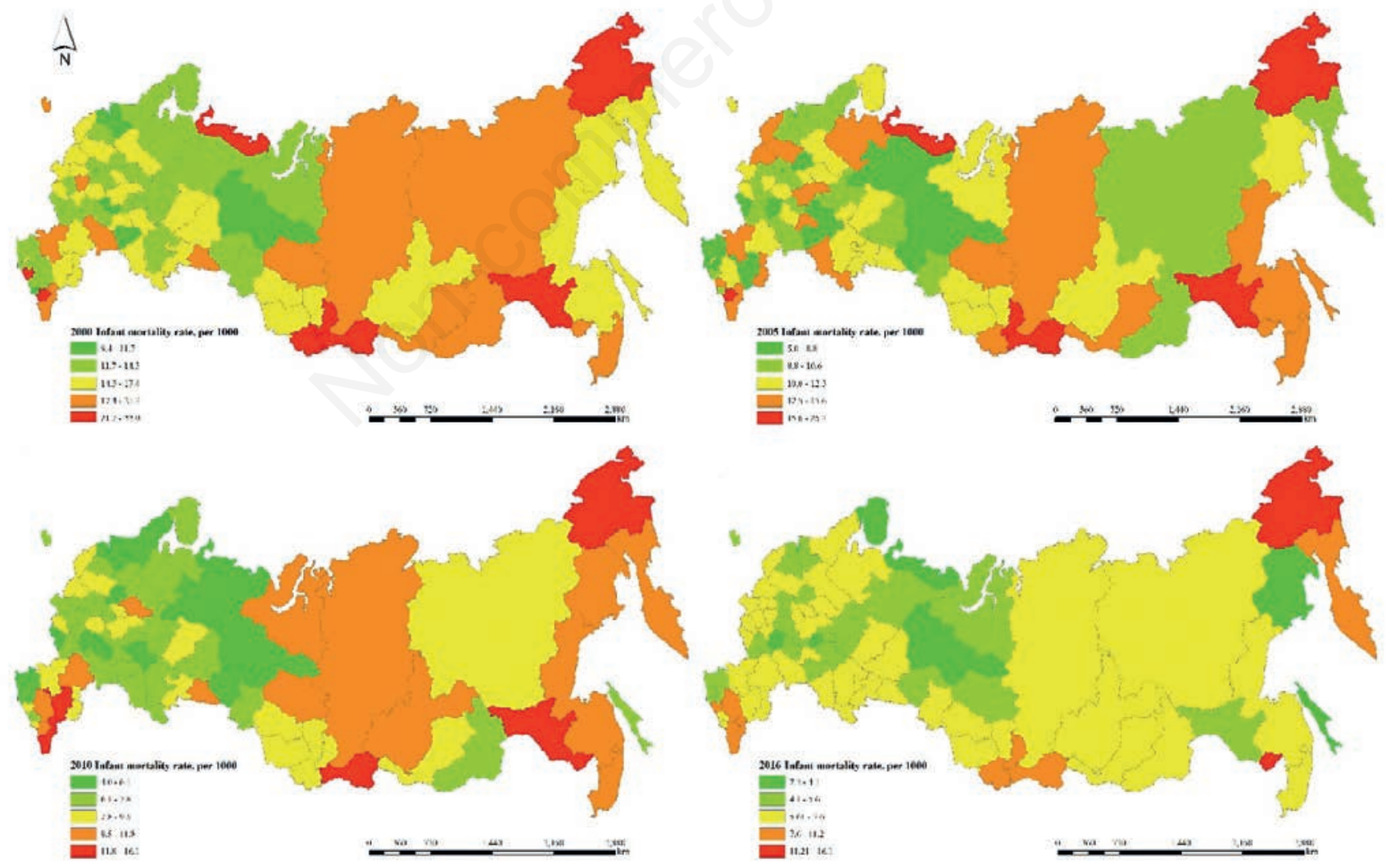

Figure 2. The spatial distribution of the infant mortality rate in Russia. 
abortions per 100 live births, while an increase of 1000 population in the region would relate to an increase of 3.8 AR. For spillover effects, every 100 USD increase in the per capita GRP would influence a decrease of $0.0069 \mathrm{AR}$ on average in the neighbouring regions, while every increase of 1000 people in one region could result in an increase of $6.78 \mathrm{AR}$ in the neighbouring regions. For IMR (Table 2), the estimations indicate that per capita GRP has a negative influence (at the $1 \%$ level), while AR and the total population measure have a considerably weaker but still positive influence (at the $10 \%$ and $5 \%$ levels, respectively). For the per capita GRP and the total population, the influence only exists as a direct force as no spillover effect was found, while for the AR, the influence was even larger in the neighbouring regions.

In detail, every 1000 USD increase in per capita GRP was associated with a decrease of 0.064 IMR in the region, while an increase of 1000 people in the region would relate to an increase of 2.05 IMR. AR shows a week positive influence on IMR, which means every one abortion decrease would relate to a decrease probability of 0.013 infant mortality.

\section{Discussion}

This paper should be seen against the background of the Russian demographic policy, which is defined by a number of statutory acts, most of which based on the Concept of Demographic Policy of the Russian Federation, which came into force in 2007 with the second (now current) stage of the Concept implemented from 2015 (Arkhangelsky et al., 2015). The act named On Additional Measures of State Support of Families with Children that was adopted in 2007 is regarded as a successful innovation promoting fertility and decreasing mortality. Among the demographic goals planned to be reached by 2025 , IMR is supposed to decrease from 10.2 per 1000 in 2006 and to 7.5 in 2010 followed by 5.1 in 2025 . Although this rate has experienced an obvious decline, the decent from 16.6 in 2000 to 6.5 in 2017 need to fall another 1.4 in the next four years to reach the goal. It is still high compared to that of the EU countries' average (3.4) and that of the US (5.7), but lower than some developing countries, such as China (8.0) and Ukraine (7.5).

With respect to the confounders favouring demographic and health growth, Miljkovic and Glazyrina (2015) found that the provision of job opportunities plays an important role in terms of willingness to give birth comparing to merely subsidies. Arkhangelsky et al. (2015) conclude that the introduction of maternity capital (benefits and tax refunds for families with children) through this policy raised the fertility rate in 2007-2008, while Kuklin and Vasilyeva (2015) feel that the implementation of some measures, including the President's Mother and Child Initiative for 20072011, have substantially contributed to abortion control. The prevention of abortion increase after the economic crisis in 2008 is emphasized by both publications cited above. Indeed, these measures might strongly contribute to the mitigation of IMR in less affluent countries, although the impact has been much less obvious in Russia. The eastern part of the country has a generally much higher AR compared to the western part, and the spatial distribution pattern has not changed for many years. The government attributes this situation partly to the region's high unemployment, while some scientists relate it to religion as the region has had more atheism than religious worship (Ferris-Rotman, 2018; Wang et al., 2019). The results from our study shows that there is direct influence of unemployment rate to AR as a good job market is important for an abortion decision. Other studies have implied that public health financing might play a small role on mitigation of abortion and mortality (Schell et al., 2007), however, our findings suggest that wellbeing of the society has a very strong impact. This disparity might be attributable to the increased ratio of the medical expenditure in Russia compared to previous years. Still, spending is still far behind, in fact 5 6 times less than that of developed countries. Soboleva (2015) attribute the positive demographic dynamic in recent years in Russia, particularly in Siberia, to the

Table 3. Pearson correlation.

\begin{tabular}{lcccccccc} 
& \multicolumn{4}{c}{ Abortion } & \multicolumn{3}{c}{ Infant mortality } \\
Year & 2000 & 2005 & 2010 & 2016 & 2000 & 2005 & 2010 & 2016 \\
Unemployment & $-0.645^{* *}$ & $-0.553^{* *}$ & $-0.338^{* *}$ & $-0.268^{*}$ & $0.522^{* *}$ & $0.494^{* *}$ & $0.372^{* *}$ & $0.384^{* *}$ \\
GRP & 0.017 & 0.054 & 0.056 & 0.123 & -0.113 & -0.034 & -0.16 & $-0.254^{*}$ \\
\hline LE & $-0.438^{* *}$ & $-0.587^{* *}$ & $-0.607^{* *}$ & $-0.714^{* *}$ & - & - & - & - \\
AR & - & - & - & - & $-0.379^{* *}$ & -0.076 & 0.04 & -0.037 \\
\hline Population & -0.024 & -0.204 & $-0.305^{* *}$ & $-0.320^{* *}$ & $-0.329^{* *}$ & $-0.319^{* *}$ & $-0.241^{*}$ & -0.195 \\
Urbanization & $0.498^{* *}$ & $0.344^{* *}$ & $0.346^{* *}$ & $0.371^{* *}$ & $-0.407^{* *}$ & $-0.318^{* *}$ & $-0.303^{* *}$ & $-0.371^{* *}$ \\
\hline Education & -0.183 & $0.223^{*}$ & $0.347^{* *}$ & $0.334^{* *}$ & $-0.230^{*}$ & $-0.466^{* *}$ & -0.173 & $-0.259^{*}$ \\
\hline
\end{tabular}

*Significance at $\mathrm{P}=0.05$; ** significance at $\mathrm{P}=0.01$. GRP, gross regional product; $\mathrm{LE}$, life expectancy; AR, abortion rate.

Table 4. Moran's I of abortion rate and infant mortality rate in Russia.

\begin{tabular}{lccccccccc} 
& \multicolumn{4}{c}{ Abortion } & \multicolumn{4}{c}{ Infant mortality } \\
Year & 2000 & 2005 & 2010 & 2016 & 2000 & 2005 & 2010 & 2016 \\
Moran's I & 0.467 & 0.367 & 0.366 & 0.391 & 0.147 & 0.129 & 0.313 & 0.146 \\
Z-value & 6.897 & 5.444 & 5.385 & 5.750 & 2.305 & 2.069 & 4.665 & 2.352 \\
\hline P-value & $<0.001$ & $<0.001$ & $<0.001$ & $<0.001$ & 0.021 & 0.038 & $<0.001$ & 0.018 \\
\hline
\end{tabular}


general economic improvement, which agrees with our results as GRP growth decrease AR and IMR.

We noted a negative relationship between AR and IMR in 2000 but not later, which indicates that there might be a harvest effect between AR and the IMR in earlier years. i.e. women with inferior health, low socioeconomic status or less access to prenatal health care, always have higher infant mortality (Biggs et al., 2013; Finer and Zolna, 2014; David and Collins, 2014), and higher abortion rate among these women would lead to (in relative term) lower infant mortality. This result agrees with historical experience, such as that of Nazi Germany, Communist Romania, Stalin's Soviet, present-day Poland, the US in the 1970s-1980s and even in some of its states today. A strict or outlawed abortion control can result in increased maternal mortality and even infanticide (Puffer, 1993; Edwards, 2019). However, the general abortion decline seen in recent years may mainly be attributable to family planning, i.e. use of more effective contraception (Denisov and Sakevich, 2015).

The decoupled and even positive influence of AR on IMR in recent years shown by our panel analysis of the years 2005, 2010 and 2016, indicates that regions with lower AR might also have lower infant mortality. This might attribute to the strong policies on abortion control and general improvement on health care system both at the macro (community, public health) and the micro (individual) level. For example, Arkhangelsky et al. (2015) suggest that the Healthcare Development part of the State Program of the Russian Federation contains a number of measures which may produce a tangible impact on mortality reduction. This is supported by the failure of the individual states to expand Medicaid under the Affordable Care Act in the US, which shows a higher IMR under abortion restrictions (Edvards, 2019). Indeed, public funding support for abortion is strongly, inversely associated with an increased IMR risk (Krieger et al., 2016). Although the education level, particularly that of the mother, has a positive impact on IMR mitigation (Grjibovski et al., 2002; Schell et al., 2007), we only found a positive impact via Pearson's correlation but not from the panel analysis.

The current study ascertains a favourable employment rate, GRP and wellbeing can contribute to the decrease of AR and IMR. The measures under the nation's demographic policy also provide positive influence on abortion control and infant mortality mitigation. However, one should also be aware that, the near-term demographic reform in Russia would mainly benefit from abortion control and IMR mitigation, and that excess mortality mitigation would reach to a ceiling by 2040 according to prediction (Arkhangelsky et al., 2015), while a long-term demographic growth would rely on a sound fertility support measures covering not just the financial sector, but also general business, private sector and in the end society itself.

\section{Conclusions}

By spatial panel econometric analysis at four time instances covering the first two decades of the new millennium, we have shown that abortion and infant mortality in Russia have declined significantly, and that income and wellbeing, represented by per capita GRP and life expectancy, have led to a strong decrease of abortion and infant mortality, while the size of the region where it occurs has a negative impact on infant mortality.

\section{References}

Anselin L, 1990. Spatial econometrics: methods and models. J Am Stat Assoc 85:160.

Anselin L, 1995. Local indicators of spatial association-LISA. Geogr Anal 27:93-115.

Arkhangelsky V, Bogevolnov J, Goldstone J, 2015. Critical 10 Years. Demographic policies of the Russian Federation: Successes and challenges. Uchitel' Publishing House, Moscow, Russia, pp. 126.

Baranov A, Namazova-Baranova L, Albitskiy V, Ustinova N, Terletskaya R, Komarova O, 2016. The Russian child health care system. J Pediatr 177S:S148-S155.

Biggs MA, Gould H, Foster DG, 2013. Understanding why women seek abortions in the US. BMC Women's Health 13:29.

David R, Collins J, 2014. Layers of inequality: power, policy, and health. Am J Public Health 104:S8-10.

Denisov B, Sakevich V, 2015. Abortion in Post-Soviet Russia: is there any reason for optimism? Demogr Rev 2015:50-68.

Edwards E, 2019. States pushing abortion bans have higher IMRs. Available from: https:/www.nbcnews.com/health/womenshealth/states-pushing-abortion-bans-have-higher-infant-mortality-rates-n1008481 Accessed: 30 April 2020.

Ferris-Rotman A, 2018. Putin the pro-choice champion: the Russian leader's fans among the U.S. Christian Right prefer to ignore his liberal views on abortion. Available from: https://codastory.com/disinformation/traditional-values/putinprochoice-champion/ Accessed: 30 April 2020.

Finer L, Zolna MR, 2014. Shifts in intended and unintended pregnancies in the United States, 2001-2008. Am J Public Health 104:S43-8.

Gens AB, 1926. Abortion in the RSFSR (Russian Soviet Federated Socialist Republic), Report to the All Union Congress on maternal and infant care, in M.: Protection of motherhood and infancy. [Internal report].

Grigoriev A, Ushakov D, Valueva E, 2016. Differences in educational attainment, socio-economic variables and geographical location across 79 provinces of the Russian Federation. Intell 58:14-7.

Grjibovski A, Bygren L, Svartbo B, 2002. Socio-demographic determinants of poor infant outcome in north-west Russia. Paediatr Perinat Epidemiol 12:255-62.

Ivanov D, Aleksandrovich Y, Oryol V, et al., 2017. Infant mortality in Russian federation and influence on its dynamic factors. Pediatr (St Petersburg) 8:5-14.

Krieger N, Gruskin S, Singh N, Kiang MV, Chen JT, Waterman PD, Beckfield J, Coull BA, 2016. Reproductive justice \& preventable deaths: State funding, family planning, abortion, and infant mortality, US 1980-2010. SSM Popul Health 2:277-93.

Kuklin A, Vasilyeva EV, 2015. The welfare and public health of the population of Russia: adaptation to economic volatility. Reconomy 1:57-67.

Lesage J, Pace R, 2009. Chapter 8: Spatial econometric interaction models. In: J. Lesage and R. Pace (Eds.), Introduction to spatial econometrics. CRC Press, New York, NY, USA.

Luneva I, Ivanova O, Khardikov A, Luneva I, Ivanova O, Khardikov A, Abrosimova NV, 2019. Factors influencing the birth rates in modern Russia. Rossiiskii Vestnik AkusheraGinekologa 19:14-20.

Miljkovic D, Glazyrina A 2015. The impact of socio-economic policy on total fertility rate in Russia. J Policy Model 37:961-73. 
Ministry of Labour of the Russia, 2013. Families in regions have started to receive monthly monetary payments for third childbirth; Moscow, Russia. Available from: http://www.rosmintrud.ru/videobank/366 Accessed: 30 April 2020.

National Healthcare Project, 2018. Surgut: strategy 24. Available from: https://strategy24.ru/rf/health/projects/natsional-nyyproyekt-zdravookhraneniy Accessed: 30 April 2020.

OECD, 2020. IMRs (indicator). OECD, Paris, France. Available from: doi: 10.1787/83dea506-en Accessed: 30 April 2020.

Panova O, Kulikov A, Berchtold A, Suris JC, 2016. Factors Associated with unwanted pregnancy among adolescents in Russia. J Pediatr Adolesc Gynecol 29:501-5.

Popov P, Tcherenev A, 2018. Social factors of territorial variability of life expectancy in the Russian Federation and features of the Baikal region. IOP Conference Series: Earth and Environ Sci 190:012061.

Russian government, 2019. Message from the President to the Federal Assembly. Available from: http://www.kremlin.ru/events/president/news/59863 Accessed: 30 April 2020.

Puffer RR, 1993. Family planning issues relating to maternal and infant mortality in the United States. Bull Pan Am Health
Organ 27:120-34.

Rosenberg D, Kozlov V, Libman, A 2018. Political regimes, income and health: Evidence from sub-national comparative method. Soc Sci Res 72:20-37.

Sakevich V, Denisov B 2014. Birth Control in Russia: Overcoming the state system resistance. National Research University Higher School of Economics, Moscow, Russia. Report no.WP BRP 42/SOC/2014.

Schell CO, Reilly M, Rosling H, Peterson S, Ekström AM. 2007. Socioeconomic determinants of infant mortality: A worldwide study of 152 low-, middle-, and high-income countries. Scand J Public Health 35:288-97.

Soboleva SV, 2015. Demographic situation in Siberia in the context of nationwide trends. Reg Res Russ 5:154-62.

Wang L, Huang J, Cai H, Liu H, Lu J, Yang L, 2019. A study of the socioeconomic factors influencing migration in Russia. Sustain 11:1650.

Wong D, Lee J, 2005. Statistical analysis of geographic Information with ArcView GIS and ArcGIS. Wiley, New York, NY, USA.

Zhukov V, 2018. Legislation on abortion: world trends and national interests. Sotsiologicheskie Issledovaniya 3:113-23. 